\title{
Assessment of battery storage utilization in distribution feeders
}

\author{
Abdullah A. Almehizia' ${ }^{1}$ (D) Fahad S. Al-Ismail ${ }^{2}$. Nasser S. Alohali ${ }^{3} \cdot$ Meshal M. Al-Shammari $^{4}$
}

Received: 5 February 2020 / Accepted: 5 March 2020 / Published online: 17 April 2020

(c) The Author(s) 2020

\begin{abstract}
The paper is concerned with the assessment of energy storage systems at the distribution level. Several projects related to energy storage are reviewed and analyzed for a better understanding of the motivation and benefits gained from such technology. Different applications and technologies of energy storage (ES) are identified, as well as the distinguishing characteristics of these ES technologies. The role of ES in the transition to a sustainable energy system is also identified and discussed. A sizing and location optimization study is conducted to realize the operational impact of installing battery energy storage systems (BESSs) in an existed distribution network in Riyadh, Saudi Arabia. The results will quantify the economic return that BESSs can offer for the electrical network, which would improve the decision making of the electric utility towards handling increasing load demand and power quality issues.
\end{abstract}

Keywords Distribution transformers $\cdot$ Energy storage $\cdot$ Optimization $\cdot$ Grid upgrade deferral $\cdot$ Peak shaving

\section{List of symbols}

Indices

I

$i, j, k$

$t$

Parameters

$C_{\alpha}^{\text {opex }}$

$C_{\mathrm{ESS}, \mathrm{P}}^{\text {capex }}$
Set of network busses

Network nodes

Time step index

Net present value of operation expenditure of element $\alpha$ (\$/unit)

Net present value of capital expenditure $\quad C_{\mathrm{ESS}, \mathrm{P}}^{\text {rep }}$ of the battery's power component $(\$ / \mathrm{kW})$

Abdullah A. Almehizia

aalmehizia@kacst.edu.sa

Fahad S. Al-Ismail

fsalismail@kfupm.edu.sa

Nasser S. Alohali

nalohali@kacst.edu.sa

Meshal M. Al-Shammari

ShammariMM@se.com.sa

1 National Center of Electric Systems Technology, King

Abdulaziz City for Science and Technology, Riyadh,

Saudi Arabia

2 King Fahad University for Petroleum and Minerals, Dhahran, Saudi Arabia

3 King Abdulaziz City for Science and Technology, Riyadh, Saudi Arabia

4 Saudi Electricity Company, Riyadh, Saudi Arabia

$$
C_{\mathrm{ESS}, \mathrm{E}}^{\mathrm{rep}}
$$

$C_{\mathrm{ESS}, \mathrm{P}}^{\mathrm{opex}}$

$C_{\text {ESS,E }}^{\text {capex }}$

$C_{\mathrm{ESS}, \mathrm{Epex}}^{\text {op }}$

ESS,E

$C_{\text {ESS,P }}^{\text {rep }}$
$C_{\text {ESS,E }}^{\text {rep }}$

$C_{\text {ESS,P }}$

$C_{\text {ESS,E }}$

$c_{\alpha}^{\mathrm{o \& m}}$

$C_{\mathrm{tf}}$

$C_{\mathrm{c}}$

$P_{l, t, i}$

$Q_{\mathrm{L}, t, i}$

$S_{\mathrm{tf}, i j}$

$S_{\mathrm{c}, i j}$
Net present value of operation expenditure of the battery's power component $(\$$ / $\mathrm{kW}$ )

Net present value of capital expenditure of the battery's energy component ( $\$$ / $\mathrm{kWh}$ )

Net present value of operation expenditure of the battery's energy component (\$/ $\mathrm{kWh}$ )

Net present value of the replacement cost of the battery's power component $(\$ / \mathrm{kW})$ Net present value of the replacement cost of the battery's energy component ( $\$$ / $\mathrm{kWh}$ )

Net present value of battery power conditioning system $(\$ / \mathrm{kW})$

Net present value of battery energy cost (\$/kWh)

Operation and maintenance cost of element $\alpha$ (\$/unit)

Net present value of transformer cost (\$/ kVA)

Net present value of cable cost $(\$ / \mathrm{m})$

Real power demand at bus $i(\mathrm{~kW})$

Reactive power demand at bus $i$ (kVAr)

Transformer capacity between bus $i$ and $j$

(kVA)

Cable capacity between bus $i$ and $j$ (kVA) 


$\begin{array}{ll}r_{i j} & \text { Resistance between bus } i \text { and } j(\Omega) \\ x_{i j} & \text { Reactance between bus } i \text { and } j(\Omega) \\ \Delta t & \text { Time step (h) } \\ \eta_{\mathrm{ESS}}^{\text {ch }}, \eta_{\mathrm{ESS}}^{\text {dis }} & \begin{array}{l}\text { Charge/discharge efficiency of installed } \\ \text { batteries (\%) }\end{array} \\ \beta, \gamma & \begin{array}{l}\text { Interest and inflation rates, respectively } \\ (\%)\end{array} \\ Y & \text { Project duration (years) } \\ n_{\mathrm{tr}}, n_{\mathrm{c}}, n_{\text {bat }} & \begin{array}{l}\text { Life time of newly installed transformers, } \\ \text { cables and batteries, respectively (years) }\end{array} \\ R & \text { Number of required replacements of the } \\ & \text { batteries }\end{array}$

\section{Variables}

$P_{\mathrm{ESS}, i}^{\mathrm{R}}$

$C_{\mathrm{ESS}, i}^{\mathrm{R}}$

$\delta_{\mathrm{tf}, i j}$

$\delta_{\mathrm{c}, i j}$

$P_{i j, t}$

$Q_{i j, t}$

$P_{\mathrm{ESS}, i, t}$

$P_{\mathrm{G}, i, t}$

$P_{\mathrm{g}, t, i}$

$P_{\mathrm{L}, i, t}$

$Q_{\mathrm{g}, t, i}$

$V_{i, t}, V_{j, t}$

$P_{\mathrm{ESS}, i, t}^{\mathrm{dis}}, P_{\mathrm{ESS}, i, t}^{\mathrm{ch}}$

$u_{1, i, t}, u_{2, i, t}$

$E_{\mathrm{ESS}, i, t}$
Rated power of the battery at bus $j(\mathrm{~kW})$

Rated energy of the battery at bus $j(\mathrm{kWh})$

Additional transformer capacity installed

between busses $i$ and $j$ (kVA)

Number of additional cables installed

between busses $i$ and $j$

Real power flow from bus $i$ to $j$ at time $t$

$(\mathrm{kW})$

Reactive power flow from bus $i$ to $j$ at time $t(\mathrm{~kW})$

Battery power injected in time $t$ at bus $j$

$(\mathrm{kW})$

Total power injected at bus $i(\mathrm{~kW})$

Generated real power injected at bus $i$

$(\mathrm{kW})$

Total real power demand at bus $i(\mathrm{~kW})$

Generated reactive power injected at bus $i$ (kVAr)

Voltage magnitudes at bus $i$ and $j$ at time

$t$, respectively $(\mathrm{V})$

Battery discharge/charge real power in

time $t$ at bus $i(\mathrm{~kW})$

Binary variable for the battery discharge,

charge status, respectively $(0,1)$

Battery storage capacity in time $t$ at bus $i$ (kWh)

\section{Introduction}

Power distribution networks are facing a dramatic transformation towards a more modern and practical structure, which is known as a smart grid (SG). Integrated distribution energy resources (IDER) including distribution generation (DG) and energy storage systems (ESS) become primary components of the SG scheme to contribute with the electric power generation delivered from the supply side, to meet the load demand and to enhance the system's security, reliability, and efficiency.

Existing electric grid infrastructure that has been built with substantial investment costs is currently under pressure to increase its effectiveness and efficiency. The pressure grows as we seek more services from the electrical grid without the need for more huge investments. One of the technical limitations in the way is the real-time flow of energy from generators to end consumers without energy storage as supply is required to meet the demand at all time to maintain system stability. However, recent advancements in technologies and regulations drive the electrical energy sector toward exploring energy storage applications and benefits. Fortunately, there is a way forward as utility companies modernize their current infrastructure to become smart. A smarter grid implements advanced technologies, tools, and techniques that are available to enable the power grid to work far more efficiently, reliably, cleanly, and economically affordable. Toward this ambitious goal, utilities worldwide have embarked on several implementations of grid modernization projects at various levels. One of the main components of smart grids is energy storage systems (ESS) [1,2].

Well-developed commercial low-energy ESS units are available in batteries, flywheels, superconducting magnetic storage, and compressed air storage [3]. Such promoted solutions are changing the direction which system planner used to follow for designing the expansion of the power generation capacity, transmission lines transfer capabilities, and new substation construction to serve the energy required of the future demand. Furthermore, the focus in the microgrid planning and operation development is supporting the deferral of bulk power generation expansion in the short and midterms by utilizing demand-side management (DSM) programs along with ESS to manage the load demand during the peak time [3].

The distribution scale grid-connected ESS is examined for optimal online power operation for peak demand and load smoothing management [4]. The optimization framework considers the forecasted projected load demand and upcoming plans for renewable power generation integration. Optimizing the storage size decisions and quantifying the cost reduction of ESS comparing to DSM programs are evaluated in [5]. Two-stage stochastic programming is used to model the system and to represent its uncertainties represented in the DG. The sensitivity analysis validates the advantages of utilizing the central energy storage for load control. Further literature suggests the incorporating of several factors in the planning modeling such as the net present value of the ESS, the maintenance costs, interruption costs, system upgrade, and energy loss charge to evaluate the investment feasibility and its arbitrage benefit [6].

Optimal sizing and location placement of energy storage systems have received significant attention in the literature [6-10]. In [6], the authors proposed a planning framework for ES allocation in distribution networks, which can provide 
maximum benefits. The paper concluded that ES helped reduce the total costs of utilities due to improvement in network reliability and distribution system upgrade deferral.

The research done by Das et al. [11] investigated the impact of optimally placed energy storage in distribution networks. The installed energy storage was shown to improve the voltage profiles as well as the reduction of line losses. The test case was the IEEE-33 medium voltage test system with high penetration of renewable energy sources. Two heuristic optimization solvers were used to solve the problem, namely the artificial bee colony and the particle swarm optimization methods.

\section{Energy storage technologies and applications}

Energy storage systems are considered enabling technologies for different smart grids' functionalities such as active management of network assets, network flexibility, improve power quality, self-healing, and resiliency. In addition, energy storage systems are essential components for integrating renewable energy resources [12]. Other applications for energy storage systems include micro-grids and electrification of remote areas, in which energy storage systems are used to minimize dependence on the main grid supply $[13,14]$.

\section{Technologies}

Different technologies have been adopted for energy storage in the industry, which can be generalized into three main themes, summarized in the following Table $1[15,16]$.

There are several parameters that differentiate energy storage systems from each other. These parameters are defined in the following $[2,13,17]$ :

Capacity Which represents the energy storage capability (Wh).

Specific energy It is defined as the electrical energy stored per mass $(\mathrm{Wh} / \mathrm{kg})$.

Specific power The amount of power that can be extracted from a kilogram of storage $(\mathrm{W} / \mathrm{kg})$.

Energy density The energy stored per unit volume (Wh/ $\left.\mathrm{m}^{3}\right)$.
Electrical efficiency The measure for the amount of energy that can be converted into work (\%).

Recharge rate The rate at which power can be pushed through the energy storage system (h).

Self-discharge The amount of time it takes for energy storage to discharge when unused due to current leakage and heat dissipation (h).

Depth of discharge (DOD) This term refers to the amount of utilized capacity of a battery energy storage system. Typically, expressed as a percentage of the battery's full capacity. The DOD has an inverse relation with the lifetime of the battery.

$C$-rate The rate at which the battery is charged/discharged relative to its capacity. A $1 \mathrm{C}$ discharge rate means that the battery will fully discharge in $1 \mathrm{~h} .2 \mathrm{C}$ means that the rate of discharge is twice the capacity. Thus, the battery will be fully discharged in half an hour.

State of charge (SOC) Represents the battery's current capacity as a percentage of maximum capacity.

Lifetime The service life of the energy storage unit, which mainly depends on the technology and the intensity of usage (years).

Capital cost The investment cost for the design, specification, civil work, and installation $(\$ / \mathrm{kW})$.

Operation cost The cost required for maintenance, fuel inspection, and part replacement $(\$ / \mathrm{kWh})$.

Charge/discharge cycle The number of cycles the storage system can be charged and discharged without affecting the storage capabilities significantly (cycles).

The climate of the region for which the energy storage would be installed plays a significant role in the technology selection. With an extreme high temperature of Saudi Arabia, it is necessary to carefully choose an energy storage technology that can withstand such harsh environments.

A high volume of energy storage projects worldwide is related to chemical battery energy storage systems. The three leading technologies are lithium-ion batteries, lead-acid batteries, and sodium-sulfur batteries.

\section{Applications}

Many energy storage technologies are now available in the market with different capabilities and characteristics, which make them very useful in a wide range of applications. Also,
Table 1 Energy storage technologies

\begin{tabular}{lll}
\hline Mechanical & Electrical & Chemical \\
\hline Pumped-hydro electric & Superconducting magnetic energy stor- & Lead-acid batteries \\
& age (SMES) & \\
Flywheels & Supercapacitors & Nickle cadmium battery \\
Compressed air energy system & & Sodium sulfur battery \\
(CAES) & & Lithium-ion battery \\
\hline
\end{tabular}


energy storage systems can be designed and built in different sizes and capacities and can be placed at various locations throughout the grid ranging from being distributed at consumers' levels to being located at transmission level as a utility-scale storage system. There are two major factors

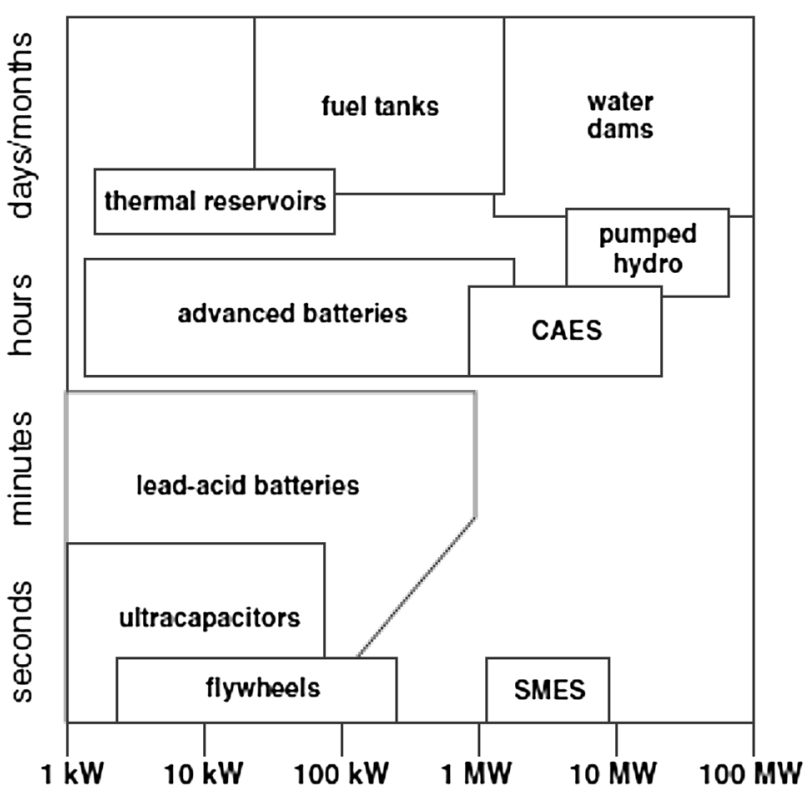

Fig. 1 Energy management, power quality, and ride-through storage applications [4] that characterize the type of application of an energy storage system: the amount of stored energy and the rate of energy transferred. [12, 18-20]. Figure 1 demonstrates different ESS technologies based on typical capacities and discharge rates, where the $x$-axis represents the size of the energy storage and the $y$-axis represents the possible discharge time for different storage technologies. The ESS size and charge/discharge rates depend on several factors, including the application for which the ESS is used. Table 2 summarizes different ESS applications and their technical requirements.

Several energy storage demonstration projects are being conducted to evaluate various distribution-level storage technologies including batteries, compressed air and flywheels systems. These pilot projects are assessing its economic and technical performance for different system configuration and application like load management, frequency control, voltage regulation and solving the intermittency problem associated with renewable energy integration [21]. An example of a demonstrating project is reported in [22], the storage is used to provide ancillary services by responding to the regulation signals send by Independent System Operator (ISO). Details analysis of the energy storage project cost-effective along with the lessons learned are demonstrated [23].

The United States Department of Energy (DOE) has a database of energy storage projects worldwide which includes different energy storage technologies [21]. China, the United States of America and Japan are considered world leaders in regarding energy storage installation capacity. As reported by

Table 2 Technical considerations for grid applications of battery energy storage systems [8]

Grid application

Arbitrage: Electric energy time-shift involve the storage of energy during periods of low prices or excess of renewable energy, which then can be used or sold at a later time when the prices are high or at times of low renewable output

Electric supply capacity: utilizing energy storage to defer or reduce the need to buy new central station generation capacity or purchasing capacity in the wholesale electricity marketplace

Regulation: part of the ancillary services. It involves managing interchange flows within the network and handle momentary variations in demand within the control area for maintaining system frequency

Voltage support: provision of reactive power from energy storage rather than the power plants placed near large loads

Load following/Ramping up of renewables: characterized by power output that generally changes as often as every several minutes. The output changes in response to the changing balance between electric supply and load within a specific area

Transmission/distribution upgrade deferral: delaying and in some cases avoid utility investments in transmission/distribution system upgrades, by utilizing energy storage to relive heavily loaded lines as well as reduce the need for upgrading distribution transformers to handle increase in demand
Technical consideration

Typical storage size: $1-500 \mathrm{MW}$

Discharge duration: $<1 \mathrm{~h}$

Minimum cycles/year: +250

Typical storage size: $1-500 \mathrm{MW}$

Discharge duration: $2-6 \mathrm{~h}$

Minimum cycles/year: 5-100

Typical storage: $10-40 \mathrm{MW}$

Discharge duration: $15 \mathrm{~min}$ to $1 \mathrm{~h}$

Minimum cycles/year: 250-10,000

Typical storage size: $1-10 \mathrm{MVAr}$ Discharge duration: Not applicable Minimum cycles/year: Not applicable Typical storage size: 1-100 MW

Discharge duration: $15 \mathrm{~min}$ to $1 \mathrm{~h}$

Minimum cycles/year: not applicable

Transmission:

Typical storage size: $10-100 \mathrm{MW}$

Discharge duration: 2-8 h

Minimum cycles/year: 10-50

Distribution:

Typical storage size:

500 kW-10 MW Discharge duration: $1-4 \mathrm{~h}$

Minimum cycles/year: 50-100 
the DOE, the installation capacity of energy storage is approximately $187.8 \mathrm{GW}$ divided over different technologies [24].

\section{The role of energy storage in the energy transition process}

The usage of variable renewable energy (VRE) resources will require high flexibility to be successfully integrated with the main grid. Fortunately, energy storage systems can be utilized to serve as a buffer for the inherency of VRE resources and allow for the dispatchability of such resources to some extent thus decoupling the supply-demand requirement [25]. EES can also enhance other levels of electricity value chain, which includes reducing the need for cycling of base load generation and increasing its average generation power. Also, EES could help enhancing the overall chain efficiency while reducing the operation of high cost peaking units. EES can relieve grid congestion and can smooth frequency and voltage fluctuations, ensuring grid reliability and security [26].

One of the biggest challenges for the transition from fossil fuels to sustainable energy sources is flexibility of the grid by meeting the ramping down of solar in the afternoon or when the wind speed reduces to lower than expected values. Energy storage in this situation can be used to provide the necessary flexibility required to maintain system balance, which would lower the burden of the ramping requirements for conventional generators.

Energy storage deployment could facilitate the electrification heating, and cooling sectors and support the roll-out of very fast charging infrastructure for electric vehicles, particularly in areas with weak grids. Industrial consumers can utilize storage to reduce consumption peaks, and to provide back-up power if there is a black-out.

Behind the meters, energy storage technologies can enable householders to contribute to the energy transition. In the sense that they provide householders the ability to store their energy for use at a later time, but are also an important element in enabling new energy practices and paradigms such as sharing and trading energy. The use of residential energy storage can help householders to become more autonomous in their energy supply with the integration of photovoltaic (PV) systems, in which reliance on grid power would be reduced. Domestic storage may also be used for demand response to help stabilize the grid [27].

\section{System modeling}

The modeling phase is the essence of being able to assess the feasibility of installing energy storage at the distribution level. Accurate models are of paramount importance to correctly quantify the impact, and potential benefits energy storage can provide to the system. In this paper, the distribution network and energy storage components are the major components of the simulation. Other elements such as the power electronics devices used as an interface between the energy storage and the network can be easily introduced in the model as a simple efficiency factor $[11,14,28]$.

\section{Network model}

There are two major components representing the distribution network. The transformers and the distribution lines (cables/ overhead). To model these two components, it is necessary to identify their impedances. The network is shown in Fig. 3, where it depicts a radial medium voltage distribution feeder $(13.8 \mathrm{kV})$ with 12 distribution transformers.

\section{BESS model}

A generic model is used to represent the battery storage system. However, certain parameters within the model can be chosen to represent different battery technologies such as the efficiency of the batteries for charging and discharging, in this paper, lithium-ion batteries where assumed for all simulation. Thus, the charging/discharging efficiency was fixed [11, 28].

\section{Load model}

The load demand on each transformer is represented by an hourly time series of constant power values.

\section{Cost functions}

The cost functions are related to the net present cost of the batteries, transformers, and the cables [6,29]. The operation and maintenance cost is assumed to occur each year of the components' lifetime.

$C_{\alpha}^{\mathrm{opex}}=c_{\alpha}^{o \& m} \sum_{y=1}^{Y}\left(\frac{1+\beta}{1+\gamma}\right)^{y}$

$\alpha \in\{$ EES, transformer, cables $\}$

$C_{\mathrm{ESS}}^{\mathrm{rep}}=c_{\mathrm{bat}}^{\mathrm{rep}} \sum_{r=1}^{R}\left(\frac{1+\beta}{1+\gamma}\right)^{r n_{\mathrm{ESS}}}$,

$R=\operatorname{INT}\left(\frac{Y}{n_{\mathrm{ESS}}}\right)$,

$C_{\mathrm{ESS}, \mathrm{P}}=C_{\mathrm{ESS}, \mathrm{P}}^{\mathrm{capex}}+C_{\mathrm{ESS}, \mathrm{P}}^{\mathrm{opex}}+C_{\mathrm{ESS}, \mathrm{P}}^{\mathrm{rep}}$, 
$C_{\text {bat,E }}=C_{\mathrm{ESS}, \mathrm{E}}^{\mathrm{capex}}+C_{\mathrm{ESS}, \mathrm{E}}^{\mathrm{opex}}+C_{\mathrm{ESS}, \mathrm{E}}^{\mathrm{rep}}$,

$C_{\lambda}=C_{\lambda}^{\text {capex }}+C_{\lambda}^{\text {opex }}$

$\lambda \in\{$ transformer, cables $\}$.

\section{Optimization formulation}

The main objective of this project is to quantify and address the benefits provided by an energy storage system (batteries) for a distribution network. The optimization model is constructed to find the optimal capacity and location within the distribution network of the BESS. As such, the optimal solution will provide optimal $\mathrm{kWh}$ and $\mathrm{kW}$ of the battery to be installed as well as the transformer and cable expansion required. The complete optimization model is described below [30, 31]:

$$
\min \sum_{i \in I} C_{\mathrm{ESS}, \mathrm{P}} P_{\mathrm{ESS}, i}^{\mathrm{R}}+C_{\mathrm{ESS}, \mathrm{E}} E_{\mathrm{ESS}, i}^{\mathrm{R}}+\sum_{\substack{i \in I \\ i \neq j}} \sum_{j \in I} C_{\mathrm{tf}} \delta_{\mathrm{tf}, i j}+C_{\mathrm{c}} \delta_{\mathrm{c}, i j} .
$$

\section{Power balance constraints}

$\sum_{j} P_{i j, t}-\sum_{k} P_{k i, t}=P_{\mathrm{G}, i, t}-P_{\mathrm{L}, i, t} \quad \forall t, \forall i, \forall k$,

$\sum_{j} Q_{i j, t}-\sum_{k} Q_{k, i, t}=Q_{\mathrm{G}, i, t}-Q_{\mathrm{L}, i, t} \begin{aligned} & \forall t, \forall i \\ & \forall j, \forall k\end{aligned}$,

$\phi_{\mathrm{c}, i j}=\left(\frac{1}{1+\delta_{\mathrm{c}, i j}}\right) \quad \forall i, \forall j$

$\phi_{\mathrm{tf}, i j}=\left(\frac{1}{1+\frac{\delta_{\mathrm{t}, i j}}{S_{\mathrm{t}, i j}}}\right) \quad \forall i, \forall j$

$P_{\mathrm{G}, i, t}=P_{\mathrm{g}, i, t}+P_{\mathrm{ESS}, i, t}^{\mathrm{dis}} \quad \forall t, \forall i$,

$P_{\mathrm{L}, i, t}=P_{1, i, t}+P_{\mathrm{ESS}, i, t}^{\mathrm{ch}} \quad \forall t, \forall i$,

$Q_{\mathrm{G}, i, t}=Q_{\mathrm{g}, i, t} \quad \forall t, \forall i$.

\section{Line flow constraints}

$-\left(1+\delta_{\mathrm{c}, i j}\right) S_{\mathrm{c}, i j} \leq P_{i j, t} \leq\left(1+\delta_{\mathrm{c}, i j}\right) S_{\mathrm{c}, i j} \quad \begin{gathered}\forall t, \forall i, \\ \forall j\end{gathered}$,

$$
\begin{aligned}
& -\left(1+\delta_{\mathrm{c}, i j}\right) S_{\mathrm{c}, i j} \leq Q_{i j, t} \leq\left(1+\delta_{\mathrm{c}, i j}\right) S_{\mathrm{c}, i j} \quad \begin{array}{r}
\forall t, \forall i,
\end{array} \\
& -\sqrt{2}\left(1+\delta_{\mathrm{c}, i j}\right) S_{\mathrm{c}, i j} \leq P_{i j, t}+Q_{i j, t} \leq \sqrt{2}\left(1+\delta_{\mathrm{c}, i j}\right) S_{\mathrm{c}, i j} \quad \underset{\forall t, \forall i,}{\forall j},
\end{aligned}
$$

$-\sqrt{2}\left(1+\delta_{\mathrm{c}, i j}\right) S_{\mathrm{c}, i j} \leq P_{i j, t}-Q_{i j, t} \leq \sqrt{2}\left(1+\delta_{\mathrm{c}, i j}\right) S_{\mathrm{c}, i j}$

\section{Transformer flow constraints}

$$
\begin{array}{cc}
-\left(S_{\mathrm{tf}, i j}+\delta_{\mathrm{tf}, i j}\right) \leq P_{i j, t} \leq\left(S_{\mathrm{tf}, i j}+\delta_{\mathrm{tf}, i j}\right) & \forall t, \forall i, \\
& \forall j, \\
-\left(S_{\mathrm{tf}, i j}+\delta_{\mathrm{tf}, i j}\right) \leq Q_{i j, t} \leq\left(S_{\mathrm{tf}, i j}+\delta_{\mathrm{tf}, i j}\right) & \forall t, \forall i, \\
\forall j,
\end{array}
$$

$-\sqrt{2}\left(S_{\mathrm{tf}, i j}+\delta_{\mathrm{tf}, i j}\right) \leq P_{i j, t}+Q_{i j, t} \leq \sqrt{2}\left(S_{\mathrm{tf}, i j}+\delta_{\mathrm{tf}, i j}\right) \quad \underset{ }{*} \quad \forall i$,

$-\sqrt{2}\left(S_{\mathrm{tf}, i j}+\delta_{t f, i j}\right) \leq P_{i j, t}-Q_{i j, t} \leq \sqrt{2}\left(S_{\mathrm{tf}, i j}+\delta_{\mathrm{tf}, i j}\right) \quad \forall t, \forall i$,

\section{Energy storage system constraints}

$0 \leq P_{E S S, i, t}^{d i s} \leq P_{E S S, i}^{R} u_{1, i, t} \quad \forall t, \forall i$,

$-P_{\mathrm{ESS}, i}^{\mathrm{R}} u_{2, t, i} \leq P_{\mathrm{ESS}, t, i}^{\mathrm{ch}} \leq 0 \quad \forall t, \forall i$,

$u_{1, i, t}+u_{2, i, t} \leq 1 \quad \forall t, \forall i$

$E_{\mathrm{ESS}, i, t+1}=E_{\mathrm{ESS}, i, t}-\left(\frac{P_{\mathrm{ESS}, i, t}^{\mathrm{dis}}}{\eta_{\mathrm{ESS}}^{\mathrm{dis}}}-\eta_{\mathrm{ESS}}^{\mathrm{ch}} P_{\mathrm{ESS}, i, t}^{\mathrm{ch}}\right) \Delta t \quad \forall t, \forall i$,

$E_{\mathrm{ESS}, i}^{\min } \leq E_{\mathrm{ESS}, i, t} \leq E_{\mathrm{ESS}, i}^{\mathrm{R}} \quad \forall t, \forall i$

Voltage drop constraints

$\left|V_{i, t}\right|-\left|V_{j, t}\right|=\frac{\left(r_{i j} \phi_{c, i j} P_{i j, t}+x_{i j} \phi_{c, i j} \phi_{t f, i j} Q_{i j, t}\right)}{\left|V_{0}\right|} \quad \begin{gathered}\forall t, \forall i, \\ \forall j\end{gathered}$,

$V_{i}^{\min } \leq V_{i, t} \leq V_{i}^{\max } \quad \forall t, \forall i$

$\delta_{\mathrm{c}, i j} \in \mathbb{N} \quad \forall i, \forall j$,

$P_{\mathrm{ESS}, i}^{\mathrm{R}}, E_{\mathrm{ESS}, i}^{\mathrm{R}}, \delta_{\mathrm{tf}, i j}, \delta_{\mathrm{c}, i j} \geq 0 \quad \forall i, \forall j$. 
The objective function (7) is to minimize the total net present cost of the installation of battery energy storage, additional transformers, and cables. The first two constraints represented by the equality constraints (8) and (9) are the power balance constraints, which is to ensure that the load demand is satisfied at each time instance for active and reactive power, respectively. Equations (13) and (14) define the factor for calculating the equivalent values of the resistive and reactive component of the network. Since the solution of the optimization problem involves the addition of new cables and transformers, the network topology will change, which will change the equivalent impedance of the network. The equality constraints (15) and (16) are the definition for the total power generation and load injection at bus $i$, respectively.

Inequality constraints (15)-(22) are for ensuring enough transformer and cable capacity are available to handle the active and reactive power flows through them. Constraints (23) and (24) are to limit the power discharge and charge from the battery at bus $i$ in time $t$ to its rated value. The inequality constraint (25) is to ensure that the battery status at bus $i$ in time $t$ is strictly either be charging, discharging, or idle. Equation (26) is to calculate the amount of energy available for the battery at bus $i$ at the beginning of the next time step. Constraint (27) ensures that the capacity of the energy storage at bus $i$ in time $t$ does not exceed its rated energy capacity and provides a lower limit for energy capacity.

Constraint (28) is related to the voltage drop between bus $i$ and $j$ if they are connected at each time instant $t$. Constraint (29) ensures that the voltage at each bus is within a specific limit for each period $t$. Constraint (30) is to define the variable associated with cable capacity expansion to be integers. Finally, constraint (31) is to ensure all the variables are non-zero. A flowchart of the optimization algorithm is shown in Fig. 2.

\section{Case studies}

The models constructed were implemented in the General Algebraic Modeling System (GAMS) to solve the optimization problem. The test system is a distribution feeder part of a substation network in Riyadh, Saudi Arabia. The data in Table 3 were collected from several references including the Saudi Arabian Monetary Authority, documents from the Saudi Electricity Company (SEC) as well as references [32, 33] (Fig. 3).

\section{Simulation results}

Comprehensive simulations involved solving the optimization problem with 50 different scenarios. For the scenarios

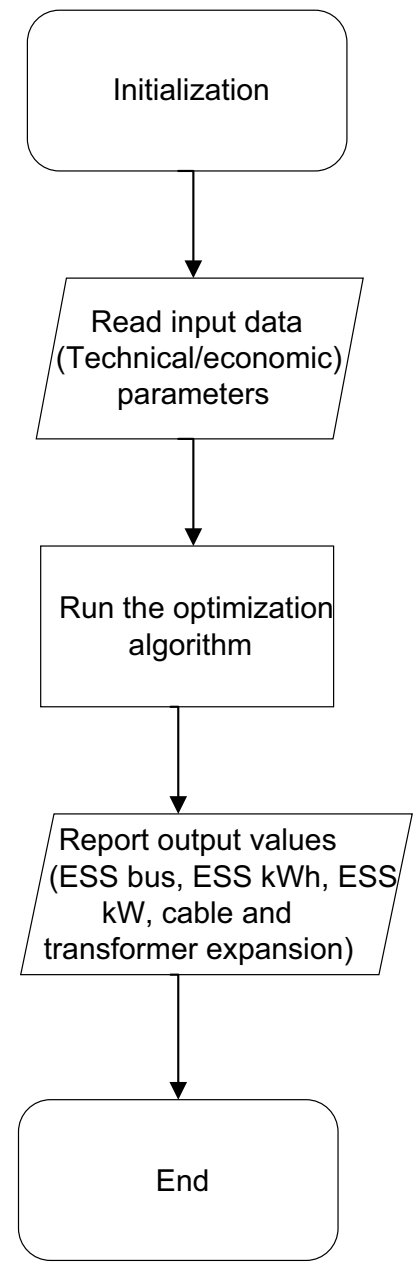

Fig. 2 Flowchart of the optimization algorithm

involving the current battery energy storage prices under different loading and transformer capacity schemes, the battery storage system was not a feasible solution. Meaning that the results of the optimization algorithm did not include energy storage as a solution. Since there are many simulation results to report, only the ones with feasible battery storage system is reported here.

- Case A-1: Peak load is $120 \%$ of nominal transformer capacity

- Case A-2: Peak load is $160 \%$ of nominal transformer capacity

- Case B-1: Transformer capacity is reduced to $50 \%$ of nominal

- Case B-2: Transformer capacity is reduced to $80 \%$ of nominal. 
Fig. 3 Test system

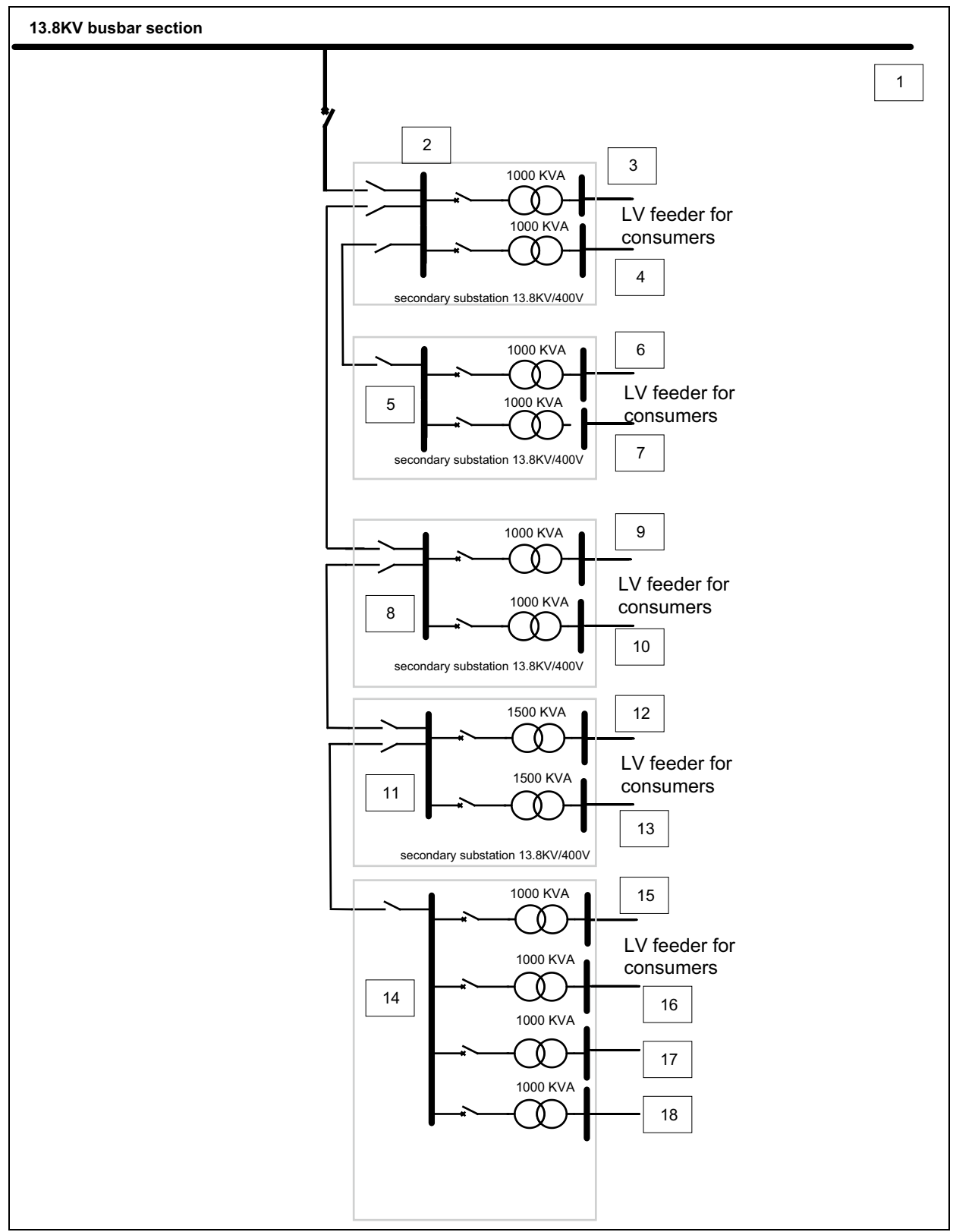

\section{Discussion}

The simulations were done to investigate the economic viability of utilizing battery energy storage systems at the distribution network. As stated previously in the paper, energy storage has the potential to serve various applications and provide different benefits to the network. From the many simulations that were carried out, it was noticeable that battery energy storage system with the current prices is not an economical choice for substation upgrade deferral or even for new construction of substations. The energy storage only became viable when the cost is only $20 \%$ ( $80 \%$ cost reduction) of the assumed current prices that is reported in Table 3. At this level of cost reduction, the energy storage prices are competitive with the cost of transformers, which is the reason for having a simulation solution that involved battery energy storage systems.

From the results section, Tables 4 and 5 shows the result of the simulation assuming the energy storage prices at $20 \%$ of current reported values. Two peak load scenarios were assumed $120 \%$ and $160 \%$ of each transformer nominal capacity. For example, transformers with a nominal capacity of $1000 \mathrm{kVA}$ would have a peak load of $1200 \mathrm{kVA}$ for the $120 \%$ peak load scenario. For the same scenario, the 1500 $\mathrm{kVA}$ transformers would have a peak load of $1800 \mathrm{kVA}$.

The peak load variation scenarios displayed an increase in energy storage capacity as the peak load increased. Transformers and cables expansion were still needed, although 
Table 3 System economic parameters

\begin{tabular}{|c|c|c|}
\hline Parameter & Unit & Value \\
\hline$\beta, \gamma$ & $\%$ & $-1.4,2.7$ \\
\hline$C_{\text {bat, } \mathrm{P}}^{\text {capex }}$ & $\$ / \mathrm{kW}$ & 600 \\
\hline$C_{\text {bat, E }}^{\text {capex }}$ & $\$ / \mathrm{kWh}$ & 300 \\
\hline$C_{\text {tr }}^{\text {capex }}$ & $\$ / \mathrm{kVA}$ & 427.17 \\
\hline$C_{\mathrm{c}}^{\text {capex }}$ & $\$ / \mathrm{m}$ & 88 \\
\hline$C_{\text {bat,P }}^{\text {opex }}$ & $\$ / \mathrm{kW}-\mathrm{yr}$ & $0.01 C_{\text {bat,P }}^{\text {capex }}$ \\
\hline$C_{\text {bat, E }}^{\text {opex }}$ & \$/kWh-yr & $0.02 C_{\text {bat, } \mathrm{E}}^{\text {capex }}$ \\
\hline$c_{\text {bat }, \mathrm{P}}^{\text {rep }}$ & $\$ / \mathrm{kW}$ & $0.75 C_{\text {bat, } \mathrm{P}}^{\text {capex }}$ \\
\hline$c_{\mathrm{bat}, \mathrm{E}}^{\text {rep }}$ & $\$ / \mathrm{kWh}$ & $0.75 C_{\text {bat, } \mathrm{E}}^{\text {capex }}$ \\
\hline$C_{\mathrm{tr}}^{\mathrm{opex}}$ & \$/kVA-yr & 68.83 \\
\hline$C_{\mathrm{c}}^{\mathrm{opex}}$ & \$/kVA-yr & $0.001 C_{\mathrm{c}}^{\text {capex }}$ \\
\hline$Y, n_{\mathrm{tr}}, n_{\mathrm{c}}, n_{\mathrm{bat}}$ & years & $30,30,30,10$ \\
\hline
\end{tabular}

energy storage system in principle can be used to offset these components.

Tables 6 and 7 are the simulation results for the same energy storage cost assumption at $20 \%$ of current prices. The peak load for each transformer was fixed at $100 \%$ of each transformer nominal capacity as such a $1000 \mathrm{kVA}$ and $1500 \mathrm{kVA}$ transformers will have a peak load of $1000 \mathrm{kVA}$ and $1500 \mathrm{kVA}$, respectively. Thus, the cost of energy storage as well as the peak load level are held constant, and the capacity of each transformer in the network is varied with two scenarios $50-80 \%$ of their nominal values. To clarify, the scenario reported in Table 6 represents a 50\% of transformer capacity. This means that in this scenario, the transformer sizes were reduced to $50 \%$ of their nominal capacity thus, a $1000 \mathrm{kVA}$ transformer will be reduced to $500 \mathrm{kVA}$ and a $1500 \mathrm{kVA}$ will be reduced to $750 \mathrm{kVA}$. This particular study was performed to investigate the viability for new construction of substations to be designed at a lower than peak load capacity for the transformers and utilize energy storage for the deficit in capacity.

For all the scenarios reported in Tables 4, 5, 6 and 7, the location of the energy storage system was always at the low side of the distribution transformers, which means that the energy storage is acting as a relief for the distribution transformers.

\section{Conclusions}

The paper discusses the feasibility of installing battery storage systems at the distribution level. The main application of the battery would be to provide peak shaving of the load in time of high demand. This has the potential to defer or even eliminate the need for the installation of new transformer and/or cables to handle the peak demand.

The simulations were done to investigate the economic viability of utilizing battery energy storage systems at the distribution network. As stated previously energy storage has the potential to serve various applications and provide different benefits to the network.

From the many simulations that were carried out, it was noticeable that battery energy storage system with the current prices is not an economical choice for substation upgrade deferral or even for new construction of substations. The energy storage only became viable when

Table 4 Results for case A-1

\begin{tabular}{llllll}
\hline Bus, $i$ & ESS ratings & & Electrical apparatus & $\begin{array}{l}\text { Original capac- } \\
\text { ity, kVA }\end{array}$ & $\begin{array}{l}\text { Expansion } \\
\text { capacity, } \\
\text { kVA }\end{array}$ \\
\cline { 2 - 6 } & Power, kW & Energy, kWh & & & \\
\hline Total system & cost: $\$$ 1.209 million & - & Cable 1-2 & 9000 & 9000 \\
1 & - & - & Cable 2-8 & 9000 & 9000 \\
3 & - & - & Transformer 2-3 & 1000 & 142 \\
6 & - & - & Transformer 2-4 & 1000 & 196 \\
7 & - & - & Transformer 5-6 & 1000 & 175 \\
8 & - & 183 & & & \\
9 & 182 & 183 & Transformer 5-7 & 1000 & 145 \\
10 & 182 & 365 & Transformer 11-12 & 1500 & 67 \\
13 & 325 & - & Transformer 14-15 & 1000 & 150 \\
15 & - & - & Transformer 14-16 & 1000 & 110 \\
16 & - & 56 & Transformer 14-17 & 1000 & 128 \\
17 & 63 & - & Transformer 14-18 & 1000 & 157 \\
18 & - & & & &
\end{tabular}


Table 5 Results for case A-2

\begin{tabular}{|c|c|c|c|c|c|}
\hline \multirow[t]{2}{*}{ Bus, $i$} & \multicolumn{2}{|l|}{ ESS ratings } & \multirow[t]{2}{*}{ Electrical apparatus } & \multirow{2}{*}{$\begin{array}{l}\text { Original capac- } \\
\text { ity, kVA }\end{array}$} & \multirow{2}{*}{$\begin{array}{l}\text { Expansion } \\
\text { capacity, } \\
\text { kVA }\end{array}$} \\
\hline & Power, kW & Energy, kWh & & & \\
\hline \multicolumn{6}{|c|}{ Total system cost: $\$ 3.653$ million } \\
\hline 1 & - & - & Cable 1-2 & 9000 & 9000 \\
\hline 3 & - & - & Cable 2-8 & 9000 & 9000 \\
\hline 4 & - & - & Cable $8-11$ & 9000 & 9000 \\
\hline 5 & - & - & Cable 11-14 & 9000 & - \\
\hline 6 & - & - & Transformer $2-3$ & 1000 & 523 \\
\hline 7 & - & - & Transformer $2-4$ & 1000 & 595 \\
\hline 8 & - & - & Transformer 5-6 & 1000 & 567 \\
\hline 9 & 592 & 615 & & & \\
\hline 10 & 592 & 615 & Transformer 5-7 & 1000 & 527 \\
\hline 12 & 166 & 166 & Transformer $8-10$ & 1000 & - \\
\hline 13 & 510 & 576 & Transformer $11-12$ & 1500 & 589 \\
\hline 14 & - & - & Transformer 11-13 & 1500 & 432 \\
\hline 15 & - & - & Transformer $14-15$ & 1000 & 533 \\
\hline 16 & - & - & Transformer $14-16$ & 1000 & 480 \\
\hline 17 & 84 & 75 & Transformer $14-17$ & 1000 & 504 \\
\hline 18 & - & - & Transformer 14-18 & 1000 & 543 \\
\hline
\end{tabular}

Table 6 Results for case B-1

\begin{tabular}{llllll}
\hline Bus, $i$ & ESS ratings & & Electrical apparatus & $\begin{array}{l}\text { Original capac- } \\
\text { ity, kVA }\end{array}$ & $\begin{array}{l}\text { Expansion } \\
\text { capacity, } \\
\text { kVA }\end{array}$ \\
\cline { 2 - 4 } & Power, $\mathrm{kW}$ & Energy kWh & & & \\
\hline \multicolumn{2}{l}{ Total system } & cost: $\$ 2.961$ million & & & \\
3 & 539 & 485 & Cable 2-8 & 9000 & - \\
4 & 79 & 71 & Cable 8-11 & 9000 & - \\
6 & - & - & Transformer 2-3 & 500 & 71 \\
7 & 128 & 115 & Transformer 2-4 & 500 & 441 \\
8 & - & - & Transformer 5-6 & 500 & 479 \\
9 & 523 & 546 & & & \\
10 & 523 & 546 & Transformer 5-7 & 500 & 364 \\
12 & 104 & 104 & Transformer 8-10 & 500 & - \\
13 & 319 & 360 & Transformer 11-12 & 750 & 556 \\
14 & - & - & Transformer 11-13 & 750 & 457 \\
15 & - & - & Transformer 14-15 & 500 & 458 \\
16 & 1 & 1 & Transformer 14-16 & 500 & 424 \\
17 & 52 & 47 & Transformer 14-17 & 500 & 440 \\
18 & - & - & Transformer 14-18 & 500 & 464 \\
\hline
\end{tabular}

the cost is only $20 \%$ ( $80 \%$ cost reduction) of the assumed current prices reported in Table 3. At this level of cost reduction, the energy storage prices are competitive with the cost of transformers, which is the reason for having a simulation solution that involved battery energy storage systems. 
Table 7 Results for case B-2

\begin{tabular}{|c|c|c|c|c|c|}
\hline \multirow[t]{2}{*}{ Bus, $i$} & \multicolumn{2}{|l|}{ ESS ratings } & \multirow[t]{2}{*}{ Electrical apparatus } & \multirow{2}{*}{$\begin{array}{l}\text { Original capac- } \\
\text { ity, kVA }\end{array}$} & \multirow{2}{*}{$\begin{array}{l}\text { Expansion } \\
\text { capacity, } \\
\text { kVA }\end{array}$} \\
\hline & Power, kW & Energy, kWh & & & \\
\hline \multicolumn{6}{|c|}{ Total system cost: $\$ 1.153$ million } \\
\hline 3 & 216 & 226 & Cable 2-8 & 9000 & - \\
\hline 4 & 310 & 346 & Cable 8-11 & 9000 & - \\
\hline 6 & 51 & 58 & Transformer $2-3$ & 800 & - \\
\hline 7 & 239 & 239 & Transformer $2-4$ & 800 & - \\
\hline 8 & - & - & Transformer 5-6 & 800 & 148 \\
\hline 9 & 200 & 201 & & & \\
\hline 10 & 200 & 201 & Transformer 5-7 & 800 & - \\
\hline 11 & - & - & Transformer 8-9 & 800 & - \\
\hline 12 & 270 & 305 & Transformer $8-10$ & 800 & - \\
\hline 13 & 288 & 361 & Transformer 11-12 & 1200 & - \\
\hline 14 & - & - & Transformer 11-13 & 1200 & 7 \\
\hline 15 & 167 & 178 & Transformer 14-15 & 800 & 52 \\
\hline 16 & 6 & 7 & Transformer $14-16$ & 800 & 124 \\
\hline 17 & 93 & 110 & Transformer $14-17$ & 800 & 140 \\
\hline 18 & 143 & 143 & Transformer $14-18$ & 800 & 73 \\
\hline
\end{tabular}

Acknowledgements This project has been financially supported and technically implemented by the Joint Research and Development Center for the Distribution Sector between King Abdulaziz City for Science and Technology (KACST) and Saudi Electricity Company (SEC).

Funding This project has been financially supported and technically implemented by the Joint Research and Development Center for the Distribution Sector between King Abdulaziz City for Science and Technology (KACST) and Saudi Electricity Company (SEC).

\section{Compliance with ethical standards}

Conflict of interest The authors declare that they have no conflict of interest.

Open Access This article is licensed under a Creative Commons Attribution 4.0 International License, which permits use, sharing, adaptation, distribution and reproduction in any medium or format, as long as you give appropriate credit to the original author(s) and the source, provide a link to the Creative Commons licence, and indicate if changes were made. The images or other third party material in this article are included in the article's Creative Commons licence, unless indicated otherwise in a credit line to the material. If material is not included in the article's Creative Commons licence and your intended use is not permitted by statutory regulation or exceeds the permitted use, you will need to obtain permission directly from the copyright holder. To view a copy of this licence, visit http://creativecommons.org/licenses/by/4.0/.

\section{References}

1. Farhangi, H.: The path of the smart grid. IEEE Power Energ. Mag. 8(1), 18-28 (2010)

2. Farret, F.A., Simoes, M.G.: Integration of Alternative Sources of Energy. Wiley, Hoboken (2006)
3. Jewell, W., Gomatom, P., Bam, L., Kharel, R.: Evaluation of distributed electric energy storage and generation. Final Report for PSERC Project T-21. PSERC Publication, pp. 04-25 (2004)

4. Malysz, P., Sirouspour, S., Emadi, A.: An optimal energy storage control strategy for grid-connected microgrids. IEEE Trans. Smart Grid 5(4), 1785-1796 (2014)

5. Schroeder, A.: Modeling storage and demand management in power distribution grids. Appl. Energy 88(12), 4700-4712 (2011)

6. Awad, A.S.A., Fouly, T.H.M.E., Salama, M.M.A.: Optimal ESS allocation for benefit maximization in distribution networks. IEEE Trans. Smart Grid 8(4), 1668-1678 (2017)

7. Masteri, K., Venkatesh, B., Freitas, W.: A feeder investment model for distribution system planning including battery energy storage. Can. J. Electr. Comput. Eng. 41(4), 162-171 (2018)

8. Xie, H., Teng, X., Xu, Y., Wang, Y.: Optimal energy storage sizing for networked microgrids considering reliability and resilience. IEEE Access 7, 86336-86348 (2019)

9. Nguyen-Hong, N., Nguyen-Duc, H., Nakanishi, Y.: Optimal sizing of energy storage devices in isolated wind-diesel systems considering load growth uncertainty. IEEE Trans. Ind. Appl. 54(3), 1983-1991 (2018)

10. Naidji, I., Smida, M.B., Khalgui, M., Bachir, A., Li, Z., Wu, N.: Efficient allocation strategy of energy storage systems in power grids considering contingencies. IEEE Access 7, 186378-186392 (2019)

11. Das, C.K., Bass, O., Kothapalli, G., Mahmoud, T.S., Habibi, D.: Optimal placement of distributed energy storage systems in distribution networks using artificial bee colony algorithm. Appl. Energy 232, 212-228 (2018)

12. Kousksou, T., Bruel, P., Jamil, A., El Rhafiki, T., Zeraouli, Y.: Energy storage: applications and challenges. Solar Energy Mater. Solar Cells 120, 59-80 (2014)

13. Komarnicki, P., Lombardi, P., Styczynski, Z.: Electric Energy Storage Systems: Flexibility Options for Smart Grids. Springer, Berlin Heidelberg (2017)

14. Balducci, P.J., Alam, M.J.E., Hardy, T.D., Wu, D.: Assigning value to energy storage systems at multiple points in an electrical grid. Energy Environ. Sci. 11(8), 1926-1944 (2018). https://doi. org/10.1039/c8ee00569a 
15. NREL: Energy Storage: Possibilities for Expanding Electric Grid Flexibility (2016)

16. CEDEC: Storage as a Tool for Smart Distribution (2016)

17. Kempener, R., Borden, E.: Battery Storage for Renewables: Market Status and Technology Outlook. International Renewable Energy Agency, Abu Dhabi (2015)

18. Pearre, N.S., Swan, L.G.: Technoeconomic feasibility of grid storage: mapping electrical services and energy storage technologies. Appl. Energy 137, 501-510 (2015)

19. Das, C.K., Bass, O., Kothapalli, G., Mahmoud, T.S., Habibi, D.: Overview of energy storage systems in distribution networks: placement, sizing, operation, and power quality. Renew. Sustain. Energy Rev. 91, 1205-1230 (2018)

20. Baxter, R., Gyuk, I., Byrne, R.H., Chalamala, B.R.: Engineering energy-storage projects: applications and financial aspects [Viewpoint]. IEEE Electr. Mag. 6(3), 4-12 (2018)

21. DOE: Energy Storage Demonstration Projects smartgrid.gov. https ://www.smartgrid.gov/recoveryact/programimpacts/energystor agetechnologyperformancereports.html. (2018)

22. Seasholtz, J.: Grid-scale energy storage demonstration of ancillary services using the ultrabattery technology. East Penn Mfg. Co., Inc., Lyons, PA (United States)DE-OE0000302 United States. https://doi.org/10.2172/1349503. NETL English (2015). https:// www.osti.gov/servlets/purl/1349503

23. Bender, D., Byrne, R., Borneo, D.: ARRA energy storage demonstration projects: Lessons learned and recommendations. Sandia National Laboratories, Albuquerque, NM, Tech. Rep. SAND2015$5242(2015)$

24. DOE: DOE global energy storage database. https://www.energ ystorageexchange.org/projects/data_visualization (2019)
25. Stenclik, D., Denholm, P., Chalamala, B.: Maintaining balance: the increasing role of energy storage for renewable integration. IEEE Power Energ. Mag. 15(6), 31-39 (2017)

26. Gallo, A.B., Simões-Moreira, J.R., Costa, H.K.M., Santos, M.M., Moutinho dos Santos, E.: Energy storage in the energy transition context: a technology review. Renew. Sustain. Energy Rev. 65, 800-822 (2016)

27. Kloppenburg, S., Smale, R., Verkade, N.: Technologies of engagement: how battery storage technologies shape householder participation in energy transitions. Energies 12(22), 4384 (2019)

28. Dugan, R.C., Taylor, J.A., Montenegro, D.: Energy storage modeling for distribution planning. IEEE Trans. Ind. Appl. 53(2), 954-962 (2017)

29. Chauhan, A., Saini, R.P.: A review on integrated renewable energy system based power generation for stand-alone applications: configurations, storage options, sizing methodologies and control. Renew. Sustain. Energy Rev. 38, 99-120 (2014)

30. Lei, S., Wang, J., Chen, C., Hou, Y.: Mobile emergency generator pre-positioning and real-time allocation for resilient response to natural disasters. IEEE Trans. Smart Grid 9(3), 2030-2041 (2018)

31. Yao, S., Wang, P., Zhao, T.: Transportable energy storage for more resilient distribution systems with multiple microgrids. IEEE Trans. Smart Grid 10(3), 3331-3341 (2019)

32. Mongird, K., et al.: Energy storage technology and cost characterization report (2019)

33. NREL: Annual Technology Baseline. https://atb.nrel.gov/electricit $\mathrm{y} / 2019 /$ index.html? $\mathrm{t}=\mathrm{st}$ 